\title{
Interacciones en un entorno de aprendizaje en línea y sincrónico: ¿qué tarea proponer con GeoGebra?
}

\author{
Rhômulo Oliveira Menezes ${ }^{1}$ \\ rhominho.oliveira@hotmail.com \\ https://orcid.org/0000-0001-9042-8323 \\ Marcelo Almeida Bairral ${ }^{2}$ \\ mbairral@ufrri.br \\ https://orcid.org/0000-0002-5432-9261 \\ ${ }^{1}$ Universidade Federal do Pará (UFPA, Brasil) \\ ${ }^{2}$ Universidade Federal Rural do Rio de Janeiro (UFRRJ, Brasil)
}

Recibido: 26/05/2020 Aceptado: 03/08/2020

\begin{abstract}
Resumen
Se ilustran y analizan interacciones colaborativas de futuros profesores al proponer una tarea en un dispositivo síncrono integrado al GeoGebra. El contexto fue un curso completamente en línea desarrollado en el entorno Virtual Math Teams (VMT). Ésta es una investigación cualitativa que utiliza un estudio de caso. El marco teórico se guía por las interacciones en entornos virtuales de aprendizaje y la importancia de proponer problemas en la formación inicial de profesores de matemáticas. Se analizan dos sesiones en las que los participantes tuvieron que reformular una tarea para ser implementada usando GeoGebra. Los datos se produjeron a partir de las interacciones en el chat escrito y las construcciones en GeoGebra, registradas en el VMT y en el diario del investigador. Acciones como construir, agregar, repensar y convencer han sido importantes en el planteamiento de posibles tareas con el GeoGebra. Al mismo tiempo que los participantes interactuaron entre sí y con las construcciones de GeoGebra en el VMT, la actividad inicial se cambió, y se negociaron y agregaron nuevas ideas, lo que permitió la aparición de un conjunto de declaraciones alteradas como resultado de estas interacciones. El análisis indica enunciados sugeridos e interacciones que los han potencializado, y contenidos matemáticos que emergieron. Los resultados sugieren que las reflexiones en línea basadas en la formulación y solución de nuevos problemas pueden ir juntas.
\end{abstract}

Palabras clave: Interacciones en línea; Entorno sincrónico; Propuesta de problema; Reflexiones colaborativas; GeoGebra.

\section{Interações em um ambiente de aprendizagem online e síncrono: que tarefa propor com o GeoGebra?}

\section{Resumo}

Ilustram-se e analisam-se interações colaborativas por licenciandos em matemática na proposição de uma tarefa em um dispositivo síncrono e integrado ao GeoGebra. O contexto foi um curso totalmente online desenvolvido no ambiente Virtual Math Teams (VMT). Trata-se uma pesquisa de cunho qualitativo e que lança mão de estudo caso. O marco teórico está orientado por interações em ambientes virtuais de aprendizagem e pela importância da proposição de problemas na formação inicial de professores de matemática. São analisadas duas sessões nas quais os participantes tiveram que reformular uma tarefa para ser implementada com o uso do GeoGebra. Os dados foram produzidos a partir das interações 
no chat escrito e das construções no GeoGebra, registradas pelo VMT e pelo diário do pesquisador. Ações como construir, acrescentar, repensar e convencer foram importantes na apresentação de possíveis tarefas com o GeoGebra. Ao mesmo tempo em que os participantes interagiam entre si e com as construções do GeoGebra no VMT, a atividade inicial foi sendo modificada e novas ideias foram negociadas e acrescentadas, permitindo o surgimento de um conjunto de enunciados alterados em decorrência dessas interações. A análise indica enunciados sugeridos e interações que os potencializaram, e conteúdos matemáticos que emergiram. Os resultados sugerem que reflexões online pautadas na formulação e na solução de novos problemas podem caminhar conjuntamente.

Palavras-chave: Interações online; Ambiente síncrono; Proposição de problema; Reflexões colaborativas; GeoGebra.

\title{
Interactions in a synchronous online learning environment: what task to propose with GeoGebra?
}

\begin{abstract}
Collaborative interactions are illustrated and analyzed in the posing of a task by Prospective Mathematics Teachers in a synchronous environment with GeoGebra. The context was a completely online course developed in the Virtual Math Teams (VMT). This is a qualitative research that uses a case study. The theoretical framework is guided by interactions in virtual learning environments and the importance of problem proposing in pre-service mathematics teachers. Two sessions are analyzed in which the participants had to reformulate a task to be implemented using GeoGebra. The data were produced from the interactions (in the written chat and the constructions carried out in GeoGebra) recorded by VMT and the researcher's diary. Actions like construct, add, rethink and convince were substantial for designing tasks with GeoGebra. At the same time in which participants interacted with each other and with the GeoGebra tools in the VMT, the initial activity was being modified and new ideas were negotiated and added providing the emergence of a set of problems modified according to with these interactions. The analysis indicates suggested statements and interactions that potentiated them, and mathematical content that emerged. Results indicate that online reflections based on design and solving of new problems can be intertwined moments.
\end{abstract}

Keywords: Online interactions; Synchronous environment; Problem posing; Collaborative reflections; GeoGebra.

\section{Introdução}

O interesse pela comunicação e pela interação em aulas de matemática tem sido recorrente na pesquisa em educação matemática, seja em Portugal (Monteiro et al., 2000), seja no Brasil (Nacarato \& Lopes, 2005; Powell \& Bairral, 2006). Em aulas de matemática interações entre professor e alunos e entre alunos acontecem de formas variadas. Por exemplo, ao iniciar uma aula, os alunos conversam, entreolham-se; o professor, por sua vez, solicita silêncio com determinado tom de voz ou com outra postura (olhar, gesto) que pode dar ênfase ao seu pedido. Para além dessas formas de comunicação, ainda se costuram, nesse contexto, relações desses sujeitos em torno da disciplina matemática (Romão, 2000). 
A comunicação pode ocorrer de forma unívoca, na qual o professor transmite o conhecimento matemático para os alunos que, na visão docente, precisam estar atentos ao que lhes é explicado. A comunicação também pode ocorrer em um modelo de ensino que permite maior protagonismo discente. Posturas docentes podem determinar formas de comunicação e de interação, pois a comunicação é um processo social no qual os participantes interagem, compartilhando informações e influenciando-se mutuamente. (Ponte \& Menezes, 2000).

A interação é uma forma de comunicação (escrita, oral, gestual, pictórica, icônica, etc.) estabelecida entre sujeito(s) e sujeito(s) ou entre indivíduos e tecnologias, sendo um construto capaz de ajudar a compreender o aprendizado e o desenvolvimento profissional de sujeitos em determinados cenários, incluindo o virtual (Bairral, 2015). Não constituindo cenas estáticas (Stahl et al., 2008), as interações permitem que os sujeitos decidam em função do que pensam coletivamente (Gonçalves, 2000), e elas são importantes ao êxito de qualquer processo de ensino ou de aprendizagem (Pedrosa, 2000).

O avanço e o uso de tecnologias interativas são acentuados em nossas vidas, mas a demanda de investigação em cenários mediados por indivíduos e tecnologias (César, 2000) ainda é muito atual. Nossos focos neste $\operatorname{artigo~}^{1}$ são ilustrar e analisar interações colaborativas por licenciandos em matemática na proposição de uma tarefa ${ }^{2}$ em um dispositivo síncrono e integrado ao GeoGebra, o VMTcG. A proposição de tarefas é assumida como um processo cognitivo complexo que envolve a geração de novas atividades ou a (re)formulação de uma situação dada (Silver, 1994).

A pesquisa traz contribuição no estudo do aprendizado, que, além de focar na resolução de tarefas (Powell \& Pazuch, 2016), analisa interações de licenciandos em tempo real, voltadas à proposição de uma tarefa no GeoGebra.

\section{Constituindo ambiências para interações online focadas na proposição de problemas}

Sobre educação online, Mercado (2009) destacou um ensino que emerge da combinação de diversos materiais (impressos, auditivos, visuais e audiovisuais), viabilizados por ferramentas de comunicação síncronas e assíncronas. $\mathrm{O}$ aluno interage com os tutores,

\footnotetext{
${ }^{1}$ Fruto de um projeto de pesquisa financiado pelo CNPq. Agradecemos pesquisadores da Drexel University (Philadelphia, EUA) e da Rutgers University, Newark (New Jersey, EUA) pela interlocução constante.

2 Neste artigo entendemos que as tarefas constituem apenas uma peça da atividade formativa (tarefa+interação+colaboração). A 'atividade' é entendida como o aceite e sua efetivação, refere-se ao caminhar; a tarefa é o "exercício" a ser feito (Bairral, 2018).
} 
com outros alunos e com o ambiente virtual de aprendizagem do curso. O tempo em que acontecem os encontros ou se realizam as atividades é flexível e não necessita de um lugar fixo: pode ser realizado de casa ou do trabalho. Essas interações podem acontecer em redes sociais (Facebook, WhatsApp, etc.), ou em ambientes virtuais de aprendizagem (Plataforma Moodle, VMTcG, entre outros). A partir de Souza e Bairral (2016), a arquitetura do nosso ambiente virtual na formação inicial de professores foi constituída, visando:

- Favorecer a hipertextualidade e a multimodalidade discursiva, com a integração de linguagens diversas (áudios, textos, imagens dinâmicas ou estáticas, etc.).

- Potencializar constantemente interação síncrona e assíncrona.

- Criar ambiências nas quais o conhecimento seja construído em um processo comunicativo de negociação e de tomada de decisões que considerem experiências e atitudes dos envolvidos.

- Propor atividades formativas que estimulem a construção do conhecimento a partir de situações nas quais o sujeito possa contextualizar e problematizar seu universo cultural e suas experiências.

- Oportunizar a proposição de problemas criativos e autorais mediante reflexões com espírito colaborativo.

(Souza \& Bairral, 2016, p. 41)

Portanto, considerando que a proposição de tarefas em situações presenciais não é um processo simples (Silver, 1994), a dinâmica formativa online procurou favorecer um tempo de familiarização e engajamento no trabalho, de modo a respeitar o tempo reflexivo dos envolvidos, oportunizar o desenvolvimento de relações com a matemática, seu ensino e aprendizagem. Para isso, a elaboração de tarefas que fomentem interações entre o professor, os alunos e outras formas de apresentar a matemática mostra-se relevante (Pedrosa, 2000). Particularmente, potencializar interações online focadas na proposição de tarefas (Silver et al., 1996) ajuda-nos a criar ambiências ${ }^{3}$ formativas com futuros professores de matemática interagindo em tempo real e fisicamente distantes (Mercado, 2009; Souza \& Bairral, 2016).

Interagir é compartilhar, é refletir e produzir significados coletivamente, com ou sem tecnologias digitais. Em um ambiente como o VMTcG a interação deixa de ser acidental ou competitiva e assume um papel no qual o grupo se esforça para o trabalho e o aprendizado conjunto. Na verdade, o que alimenta a sustentação do grupo, é a cumplicidade, a coletividade. Um pequeno coletivo de indivíduos colaborando on-line, sublinha Stahl (2006), pode pensar e aprender como um grupo, não como uma soma de pessoas participando e oferecendo informações isoladamente.

\footnotetext{
${ }^{3}$ A ambiência constitui o desenho didático do cenário, as possíveis inter-relações dos sujeitos e o pertencimento (individual e coletivo). É a concretização e a efetivação do planejamento e o seu redesenho, sempre que necessário.
} 
A aprendizagem não é vista como um produto em si mesmo, mas uma conjunção de aspectos (exemplos, conceitos, concepções, sugestões, construções em tela etc.) que vão se desenvolvendo no coletivo constituído. Embora as contribuições sejam individuais o resultado é um produto do grupo, não de um sujeito apenas. Coletivos distintos desenvolvem formas próprias de interagir e, portanto, de aprender.

A proposição de tarefas é um processo formativo que envolve a geração de novas atividades ou a (re)formulação de uma situação dada ou de uma experiência (Silver, 1994). Essa proposição pode ocorrer segundo três fases: a da proposição inicial, a da resolução e a das proposições adicionais (Silver et al., 1996). Nesse contexto, sobre a aprendizagem derivada da tarefa de propor problemas a partir de um problema inicialmente dado, entendemos que os sujeitos não necessariamente os resolvem previamente, pois esse processo envolve a criação de um novo problema, mediante a modificação de condições daquele que foi dado. Tal proposição pode ocorrer previamente a um processo de resolução ou pode abordar problemas que foram gerados de uma situação natural ou vivenciados. O objetivo não é a solução de um problema apresentado, mas a criação de situações novas, analisando e considerando condições ou restrições dadas ou emergentes de seus questionamentos.

Dessa forma, considerando uma tarefa que propõe a (re)formulação de uma situação dada em um ambiente virtual online e síncrono, a aprendizagem acontece a partir da contribuição individual dos aprendizados derivados das interações dos sujeitos envolvidos na agregação de um produto comum ao grupo (Stahl et al., 2008). E nesse cenário, se futuros professores adquirirem uma capacidade generativa em sua própria atividade matemática de proposição de problemas, será razoável esperar que sua competência pessoal nessa prática não seja o maior obstáculo na incorporação de atividades de resolução de problemas em sua docência (Silver et al., 1996). Com esse princípio, buscamos também, mediante a proposição de tarefas, promover inovações curriculares na licenciatura em matemática.

\section{Metodologia}

Segundo Martins e Bicudo (2005) a pesquisa qualitativa busca uma compreensão particular, específica, peculiar, individual daquilo que se estuda, almejando sempre a compreensão e não a explicação dos fenômenos estudados. Assim, entendemos a pesquisa relatada neste artigo como sendo do tipo qualitativa, já que buscamos compreensões sobre interações colaborativas de licenciados em matemática em meio a proposição de uma tarefa em um ambiente online e síncrono integrado ao GeoGebra. 
O contexto de produção de dados para a pesquisa foi o curso "Interações e Estratégias de Modelagem no ambiente VMT com GeoGebra", proposto como projeto de extensão, submetido à Pró-Reitoria de Extensão (PROEXT) da Universidade Federal Rural do Rio de Janeiro (UFRRJ - Campus Seropédica/RJ). Com carga horária de 20 horas, foi realizado com professores em formação inicial do curso de matemática, no segundo semestre de 2018.

A equipe do curso foi composta por um coordenador, professor da UFRRJ que orientou seu planejamento e sua execução; por um doutorando, que estava fazendo doutorado sanduíche na UFRRJ e que atuou na elaboração, na organização e na mediação das sessões; por um mestrando da UFRRJ, que cuidou da criação das salas virtuais e do cadastro dos participantes no ambiente VMT; e por um graduando da iniciação científica da UFRRJ, que também atuou como mediador nas sessões.

Para o curso foram elaboradas cinco tarefas, desenvolvidas em seis sessões (uma por semana), sendo cada tarefa independente matematicamente uma da outra. Para este artigo consideramos a tarefa trabalhada nas duas sessões finais, "Propondo uma nova tarefa", que consistia na reelaboração de uma atividade de Swan (2014) e tratava do menor caminho que uma criança deveria percorrer, passando pelos quatro pontos disponibilizados na área retangular, não importando o caminho, conforme traduzida na Figura 1.

Figura 1: Atividade do playground
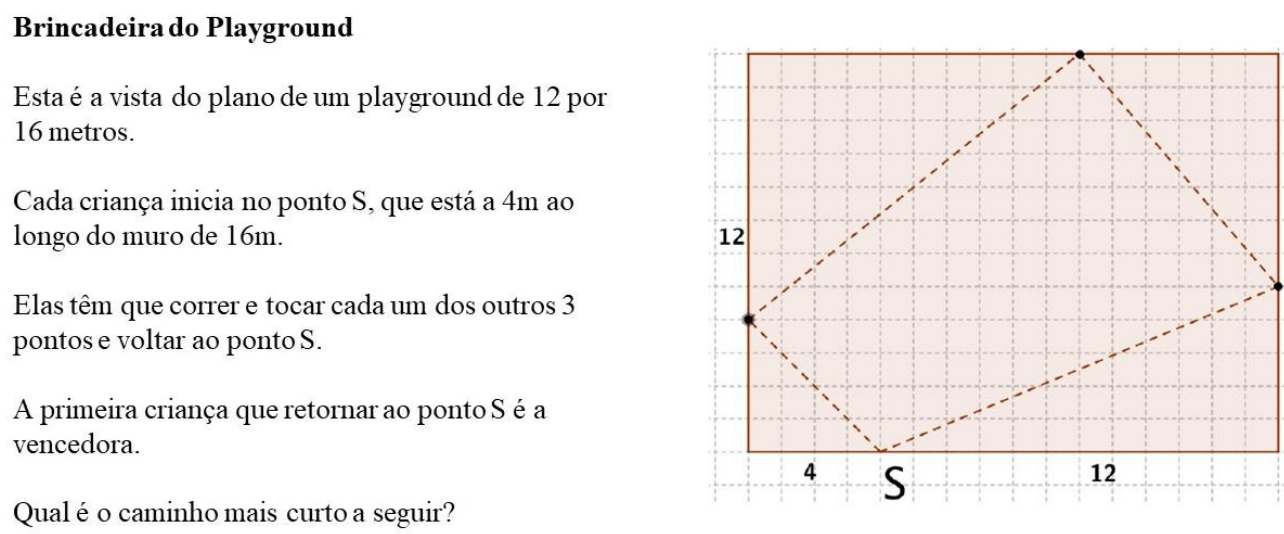

Fonte: Traduzido pelos autores de Swan (2014)

As informações textuais e pictóricas presentes na atividade de Swan (2014) sugerem que os pontos marcados no desenho são fixos, e diante desse entendimento a atividade foi apresentada aos participantes acompanhada das seguintes perguntas: "Vocês a proporiam da mesma forma, usando o GeoGebra? Como ela deveria ser proposta? Como seria o seu enunciado? O que muda (ou não) na solução, quando ela é proposta no papel quadriculado e no GeoGebra? Elaborem uma proposta para que ela seja desenvolvida com o GeoGebra". 


\section{$O$ ambiente das sessões $e$ os participantes investigados}

As sessões, uma por semana, aconteceram no VMTcG e duravam no máximo duas horas. Os sujeitos interagiram somente pelo VMTcG e somente online. Nesse ambiente os participantes podiam interagir no quadro branco, no GeoGebra e no chat, como indicado na Figura 2.

Figura 2: Elementos do VMTcG

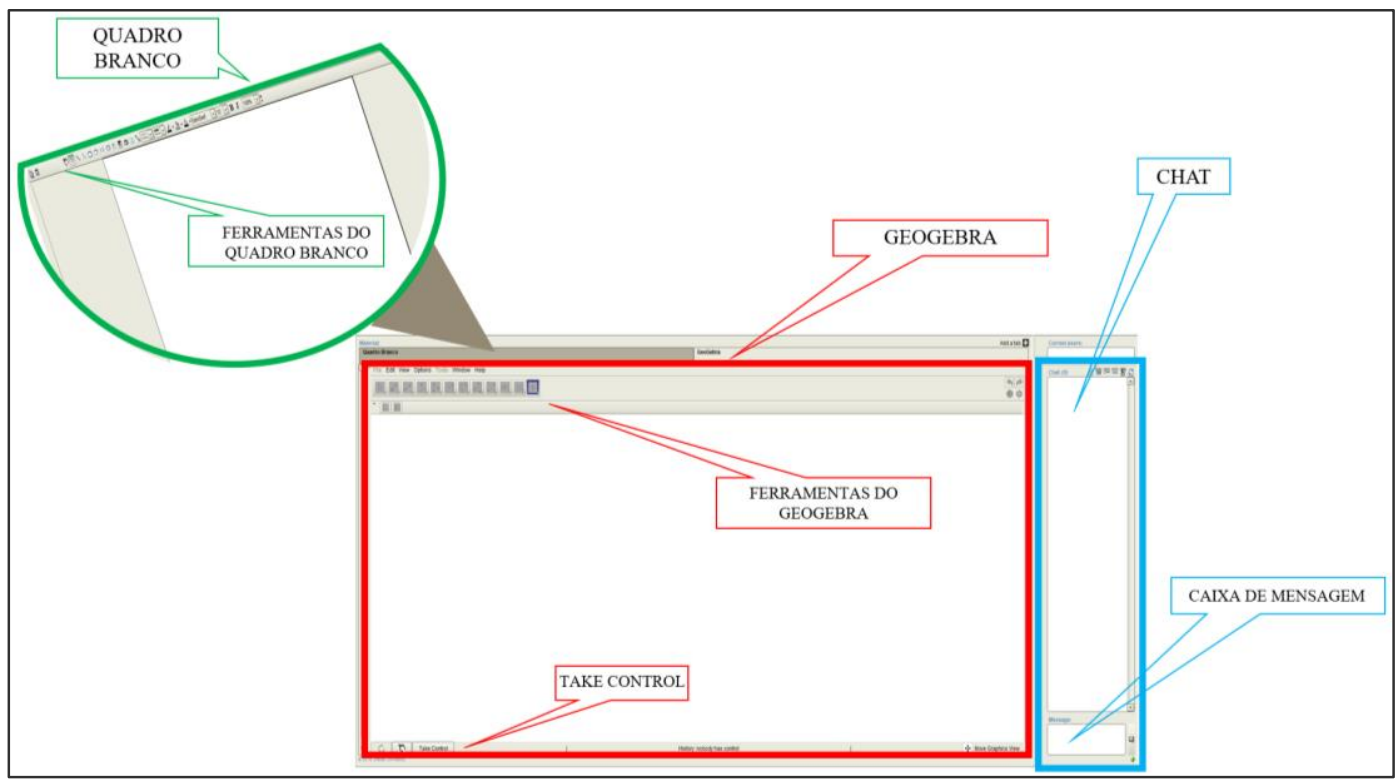

Fonte: VMTcG (2018)

As ferramentas do quadro branco são semelhantes às de editores de textos conhecidos, como o Word. Assim, era possível escrever textos, construir formas, escolher o tipo e o tamanho da fonte, inserir figuras, dentre outras ações, simultaneamente. Por outro lado, o GeoGebra apresentava ferramentas encontradas em versões sem o VMT; no entanto, a versão do VMT era disponível somente em língua inglesa, e os participantes não manipulavam as ferramentas simultaneamente, o uso se restringia a um participante por vez, e para requerer o uso era preciso que o participante clicasse no botão 'take control' .

A coordenação das ações dos participantes no quadro branco e no GeoGebra se dava por meio de mensagens trocadas simultaneamente no chat. O grupo investigado neste estudo era composto por quatro participantes identificados pelos pseudônimos: Ana, Zeca, Pedro e Paula. No momento da inscrição no curso, os participantes responderam algumas perguntas pelo Google Formulário, o que nos permitiu traçar um perfil de cada um deles, conforme resumido no Quadro 1. 
Quadro 1: Perfil dos participantes

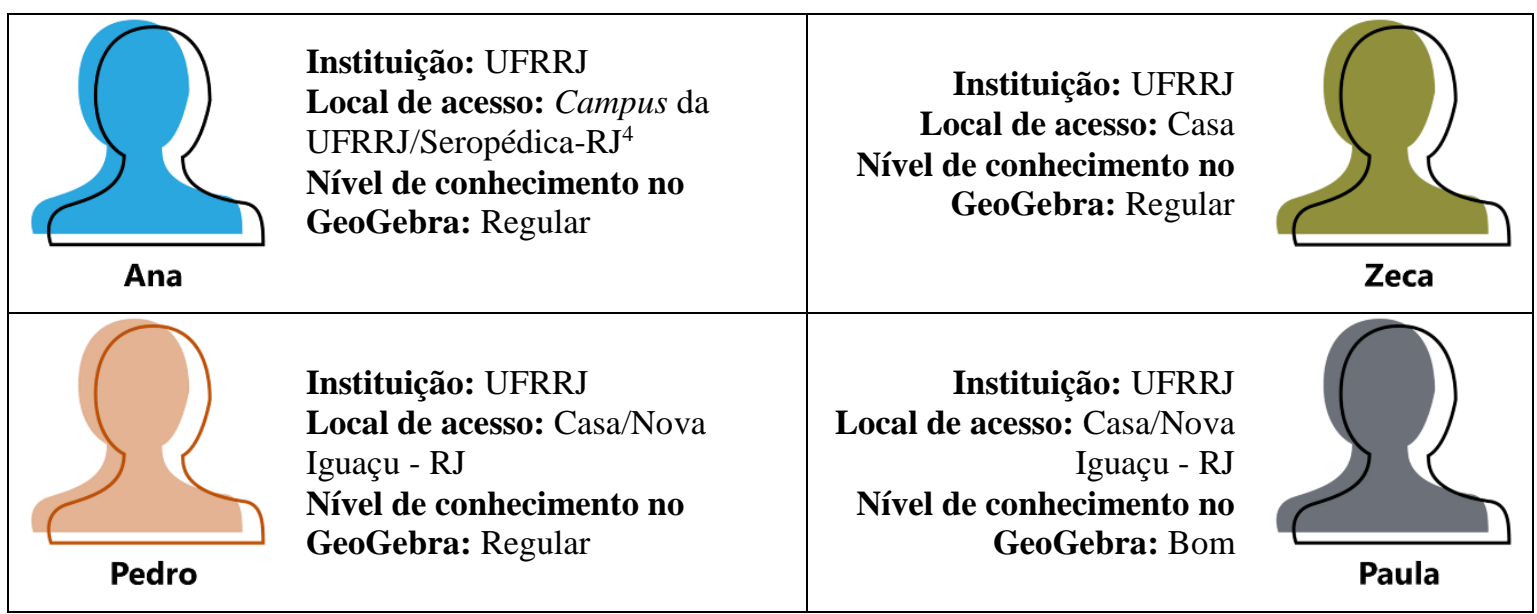

Fonte: Formulário de inscrição dos participantes (2018)

Os licenciandos demonstraram conhecimento regular do GeoGebra, não conheciam o VMTcG e não possuíam experiência com ele anterior ao curso. Portanto, essas foram as razões para escolha e análise desse caso, de natureza exploratória, pois objetivamos obter informações preliminares inerentes ao nosso objeto de estudo.

\section{Produção e análise de dados}

Os dados foram produzidos nas duas sessões da tarefa "Propondo uma nova tarefa" no VMTcG - materializados nos chats e nas construções realizadas no GeoGebra. Ao final de cada sessão no VMTcG, o mediador (primeiro autor neste artigo) registrava os acontecimentos em seu diário. Após a sessão de pesquisa, o registro rápido no diário tornase indispensável para que o pesquisador não perca informações valiosas à sua investigação (Carmo \& Ferreira, 2008). Mediante o player, o VMT permite ao pesquisador revisitar as interações online sempre que necessário.

Para análise dos dados adaptamos as fases de análise de chats de Bairral (2018), a saber: a fase 1 refere-se ao planejamento do chat; a fase 2 dedica-se à análise no coletivo; a fase 3 ocupa-se da análise personalizada; e a fase 4 aborda a meta-análise do processo. Por entender esse processo de análise de forma cíclica, Bairral (2018) sugere ao pesquisador retroalimentá-lo com informações adicionais. Por isso, mesmo sendo um processo voltado para análise de aprendizagens docentes, é permitido alterá-lo conforme o contexto e os objetivos do pesquisador. Dessa forma, adaptamos as fases desse processo para análise dos

\footnotetext{
${ }^{4}$ Por ser um ambiente robusto o VMTcG requer conexão muito boa à Internet. Portanto, perguntar aos participantes sobre o local de acesso foi necessário para a organização das sessões e para alertar os sujeitos dessa robustez e necessidade de conectividade estável.
} 
chats produzidos por professores em formação inicial do curso de matemática nas sessões da tarefa "Propondo uma nova tarefa" desenvolvidas no VMTcG, conforme os destaques em vermelho na Figura 3.

Figura 3: Processo (adaptado) de análise dos chats

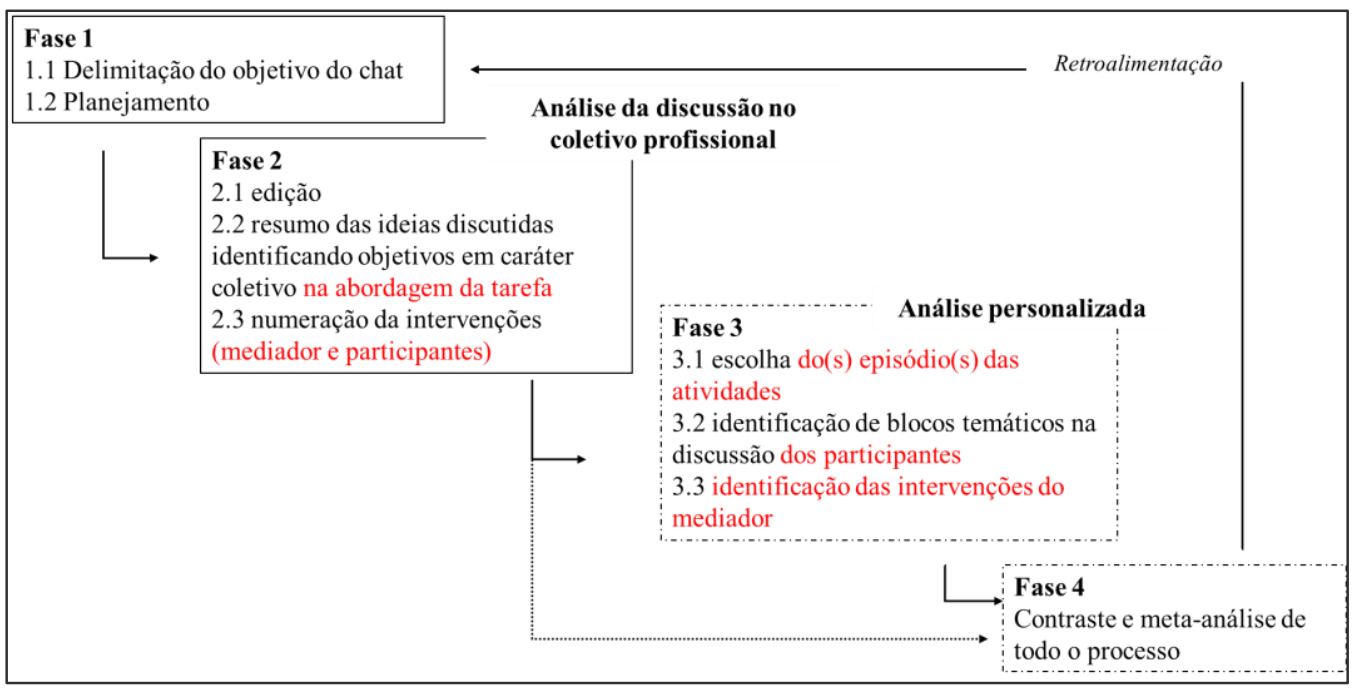

Fonte: Adaptação pelos autores de Bairral (2018)

Assim, a Fase 1 norteou o planejamento e o objetivo da tarefa 'Propondo uma nova tarefa; a Fase 2 focou na identificação de ideias gerais discutidas pelos participantes durante a sessão evidenciando os caminhos que o grupo escolheu percorrer para realizar a tarefa; a Fase 3 permitiu selecionar episódios e temas discutidos pelos participantes, para serem interpretados na Fase 4 segundo o objetivo deste artigo.

\section{Descrição e análise das sessões "Propondo uma nova tarefa"}

As três primeiras fases, do processo (adaptado) de análise dos chats, por tratarem do planejamento, da execução do chat, da seleção de episódios e de temáticas decorrentes das interações dos participantes; são propositalmente mais descritivas. A parte mais analítica foi abordada na Fase 4 em que interpretamos os dados produzidos. O processo analítico buscou ilustrar enunciados, interações e conteúdos matemáticos que emergiram das interações no VMTcG na proposição de uma nova tarefa pelos licenciandos. As fases de análise do chat foram adaptadas. Apresentaremos a seguir a análise dos dados derivados do diário de pesquisa e dos registros (chat e construções geométricas) dos participantes no VMTcG durante as sessões "Propondo uma nova tarefa". 


\section{Fase 1}

Sobre o planejamento (item 1.2, Figura 3) das sessões no VMTcG que promovessem interações entre os participantes, orientamo-nos por indicações de autores que pesquisam sobre educação online (Mercado, 2009; Souza \& Bairral, 2016). As duas últimas sessões do curso, discutidas neste artigo, focaram na proposição de tarefas. Os participantes eram licenciandos em matemática, sem experiência nesse tipo de curso e de cenário online. Portanto, deixar a reformulação de tarefas para as duas sessões finais do curso foi estratégico, de modo a respeitar o tempo de ambiência no trabalho online, o tipo de tarefa e o uso do VMTcG. A tarefa utilizada (Figura 1) lhes foi proposta somente na sessão do curso. Os participantes tinham como objetivo (item 1.1, Figura 3) reformulá-la, considerando conteúdos matemáticos e registros no quadro branco e no GeoGebra.

\section{Fase 2 e 3}

As sessões eram síncronas e tinham duração máxima de duas horas. A primeira sessão aconteceu no dia 13/11/2018, com todos os participantes reunidos (Ana, Zeca, Pedro e Paula). A segunda sessão ocorreu no dia 27/11/2018; no entanto, somente Zeca e Paula puderam participar. Ana e Pedro tiveram imprevistos e não conseguiram se reunir. Os participantes já se conheciam das sessões anteriores do curso e tinham familiaridade com as ferramentas do VMTcG.

\section{Primeira sessão "Propondo uma nova tarefa"}

A primeira sessão "Propondo uma nova tarefa" (item 2.1, Figura 3) estava prevista para começar às 19 horas. Ana chegou primeiro (19:02:36), seguida de Paula (19:04:44) e Zeca (19:16:48). Por último, Pedro, que havia avisado antes da sessão que iria atrasar (19:40:07). O atraso de um dos licenciandos não atrapalhou o andamento da sessão, na medida em que, nas sessões anteriores do curso, quando isso acontecia, o mediador resumidamente apresentava a tarefa para quem chegava depois. Como o chat escrito ficava registrado, o graduando que atrasava tinha acesso às ideias discutidas até então.

Nessa primeira sessão, o mediador postou a atividade de Swan (2014), seguida de questões iniciais que sugeriam que a reformulassem em uma nova tarefa. Os participantes focaram na reelaboração do enunciado da atividade de Swan (2014), evocando possibilidades de abordagem de conteúdos matemáticos e possibilidades do uso do 
GeoGebra na resolução da tarefa proposta. Nessa sessão não houve interações no GeoGebra. Zeca foi o primeiro a propor uma ideia para o novo enunciado:

Zeca (13/11/2018-19:48:02): Gente.

Zeca (13/11/2018-19:48:07): Pensei numas paradas aqui.

Zeca (13/11/2018-19:48:09): Vou expor.

Zeca (13/11/2018-19:49:17): Não, cada rumo até os vértices deveria ter duas opções a serem avaliadas (catetos ou hipotenusa). Na malha do GeoGebra dá para ter noção da distância.

O desenho do playground de Swan (2014) apresenta um caminho tracejado quadrangular no qual seus lados são hipotenusas de quatro triângulos, e Zeca sugeriu que houvesse diferenças na nova tarefa em relação aos catetos e à hipotenusa dos triângulos formados pelo caminho tracejado. A proposta de Zeca foi recebida com surpresa por Paula, que apresentou uma contraproposta:

Paula (13/11/2018-19:51:01): Caraca, não tinha pensado assim. Achei muito bom. Você está considerando a imagem que está ali?

Paula (13/11/2018-19:51:48): Porque eu pensei que a criança poderia fazer um caminho do tipo, saindo de $S$ e indo lá em cima primeiro.

Paula (13/11/2018-19:52:09): Envolveria triângulos também.

Posteriormente às inserções de Paula, Zeca sugeriu uma proposta de enunciado condizente com sua primeira ideia:

Zeca (13/11/2018-19:52:41): Num brinquedo playground, cada criança inicia do ponto $S$, que está a $4 \mathrm{~m}$ ao longo do muro de $16 \mathrm{~m}$. Elas têm que correr e tocar cada um dos 3 vértices pontilhados, e voltar ao ponto $S$. Sabendo que pelo caminho pontilhado existem obstáculos e sua velocidade se reduz para $1 \mathrm{~m} / \mathrm{s}$ e pelo caminho do muro a velocidade é de $2 \mathrm{~m} / \mathrm{s}$. Qual o melhor trajeto?

$\mathrm{Na}$ proposta de enunciado apresentada por Zeca fica mais claro o que, no desenho do playground, ele estava considerando como catetos e o que estava tomando como hipotenusas (Figura 4).

Figura 4: Representação da proposta de Zeca

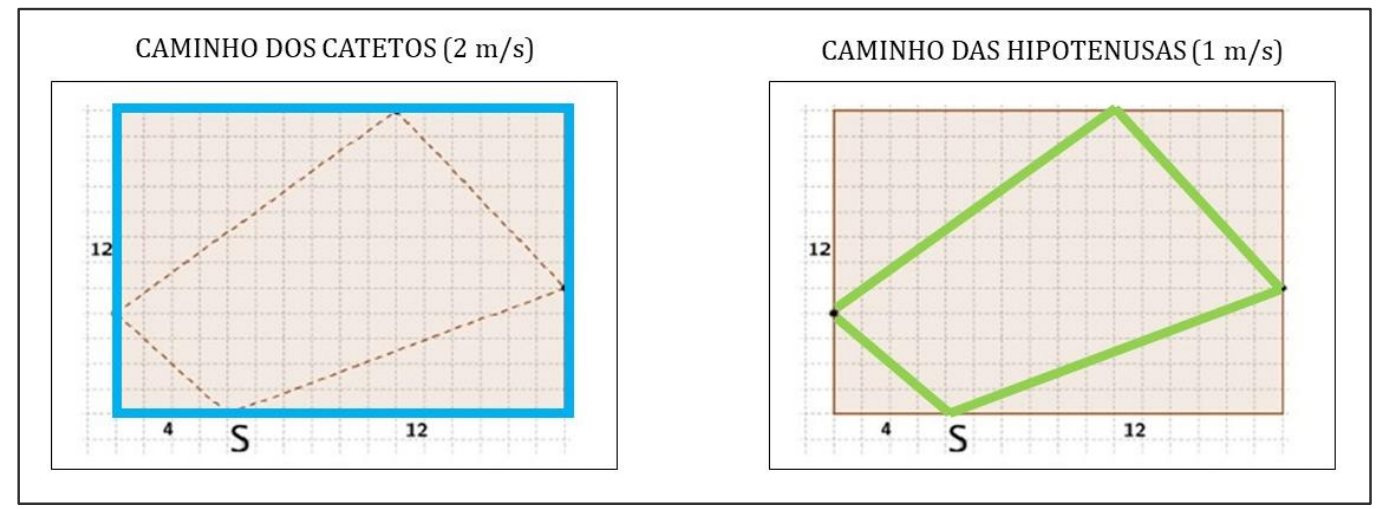

Fonte: Autores (2020) 
A proposta de Zeca esteve mais próxima das marcações originais da planta do playground apresentada por Swan (2014) ${ }^{5}$, enquanto, que Paula contrapôs sugerindo um caminho que fugiu tanto dos caminhos dos catetos, quanto do caminho das hipotenusas descritos por Zeca. Para Paula o caminho poderia partir do ponto S em direção ao muro oposto e paralelo. No entanto, Zeca inseriu na sua proposta um elemento inédito em relação à atividade de Swan (2014): a velocidade variando conforme o caminho escolhido. Esse novo elemento foi bem aceito por Paula e Pedro:

Paula (13/11/2018-19:53:26): Eu pensei envolver velocidade também.

Pedro (13/11/2018-19:53:37): Envolver velocidade é uma boa.

Paula (13/11/2018-19:53:54): Envolvendo coisas assim ficaria mais real o problema.

Pedro (13/11/2018-19:54:02): Sim.

Pedro (13/11/2018-19:54:40): Gostei dessa proposta.

Paula entendeu que agregar elementos como velocidade torna a tarefa mais verossímil. Mesmo concordando, Paula argumenta que a proposta de Zeca deve ser tomada como base; no entanto, sugere não restringir as opções de resolução a dois caminhos, pois a tarefa desenvolvida no GeoGebra potencializaria experimentar outras opções:

Paula (13/11/2018-19:57:01): Acho que podemos utilizar essa ideia como base.

Paula (13/11/2018-19:57:22): Eu acho que poderíamos não restringir a somente dois caminhos.

Paula (13/11/2018-19:58:24): Poderíamos dizer que no tracejado diminui a velocidade.

Paula (13/11/2018-19:58:33): E fora dele não.

Paula (13/11/2018-19:58:42): Qual seria o melhor caminho.

Paula (13/11/2018-19:59:18): Que aí ele teria que ver no GeoGebra outros caminhos do tipo ir lá em cima, ir para direita, depois esquerda e voltar.

Pedro (13/11/2018-19:59:36): Sim.

Paula (13/11/2018-19:59:37): Entenderam? Acho que ficou embolado.

Pedro (13/11/2018-19:59:50): Acho que deu para entender.

Paula, considerando o elemento velocidade e a potência ensejada pelo GeoGebra na resolução da tarefa, sugere mais possibilidades de respostas (Figura 5), ampliando o enunciado proposto por Zeca.

\footnotetext{
${ }^{5} \mathrm{O}$ autor delimitou a área de playground em um plano retangular de lados 12 e $16(4+12)$, como retratado na Figura 1.
} 
Figura 5: Representação da proposta de Paula

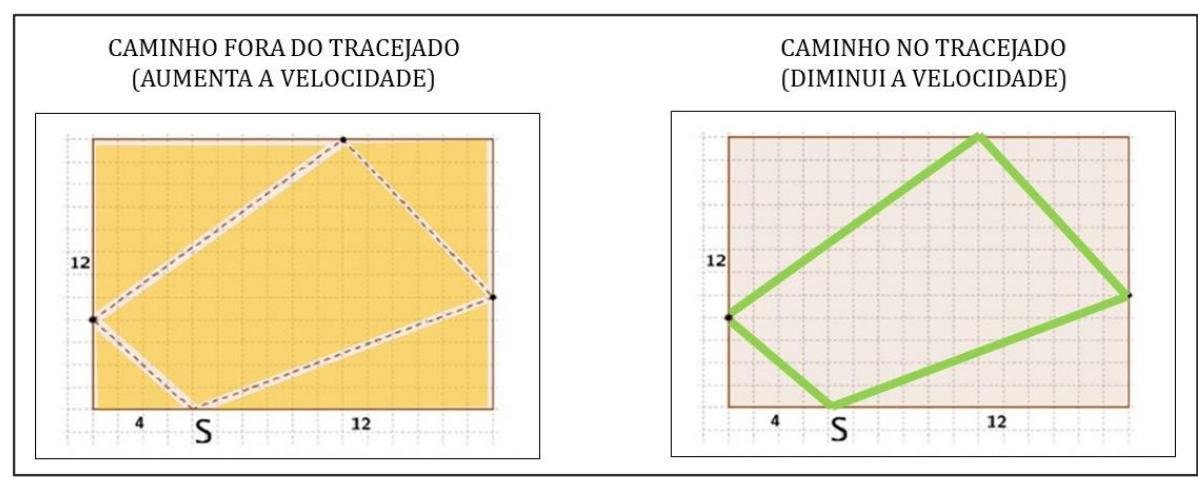

Fonte: Autores (2020)

Até o momento da proposição de Paula, Pedro aparentava concordar com ela, mas, em seguida, o participante afirmou: "eu pensei em um enunciado tendo como base o pensamento proposto pelo Zeca" (Pedro, 13/11/2018-20:19:05). Paula, por sua vez, dando sequência a suas proposições, sintetizou as ideias até então colocadas para nova tarefa no seguinte enunciado:

Paula (13/11/2018-20:27:18): Em um playground de formato retangular medindo $12 \times 16 \mathrm{~m}$, um animador de festa inicia uma brincadeira com as crianças. A brincadeira consiste em tocar os brinquedos e voltar para o ponto inicial. Vence a criança que voltar primeiro para o ponto de partida. Sabendo que sobre o caminho tracejado a velocidade máxima obtida será de $1 \mathrm{~m} / \mathrm{s}$ e pelo caminho dos muros é de $2 \mathrm{~m} / \mathrm{s}$. Qual seria o melhor caminho para a criança sair vencedora? Agora considerando que toda área fora do caminho pontilhado teria uma velocidade de $2 \mathrm{~m} / \mathrm{s}$, conseguiríamos encontrar um caminho melhor que o escolhido anteriormente?

Paula, com sua proposta de enunciado, não exclui e nem modifica a ideia sugerida por Zeca; pelo contrário, ela retoma o que Zeca tinha colocado e acrescenta ao final outro leque de opções de resolução para a nova tarefa, reunindo em um único enunciado as ideias apresentadas (Figura 6).

Figura 6: Possibilidades de resoluções

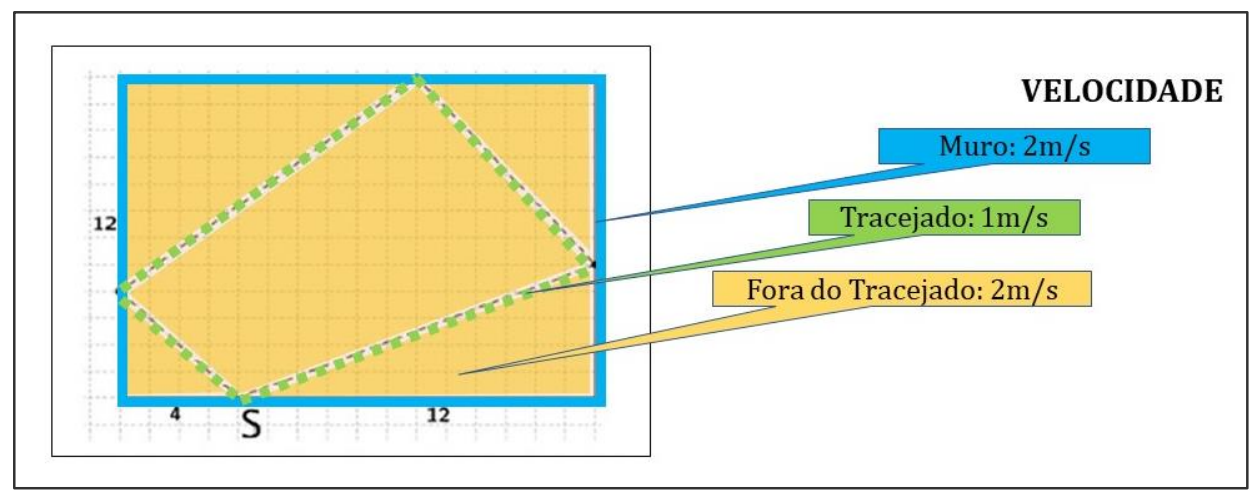

Fonte: Autores (2020) 
Tanto Pedro quando Zeca concordaram com a proposição de enunciado de Paula: Pedro (13/11/2018-20:27:51): Arrasou, Paula!; Zeca (13/11/2018-20:28:32): Show; Zeca (13/11/2018-20:28:39): Gostei também.

Nessa primeira sessão percebemos que os participantes assumiram como objetivo coletivo propor um novo enunciado (item 2.2, Figura 3). Nessa combinação de ideias e propostas em torno desse objetivo comum, escolhemos o episódio da inserção do elemento velocidade (item 3.1, Figura 3), que até então não existia na atividade inicial de Swan (2014). Nesse episódio identificamos discussões que giraram em torno de um enunciado que permitia uma quantidade limitada de resoluções e de outro, que oferecia uma multiplicidade de resoluções, levando em conta o uso do GeoGebra (item 3.2, Figura 3). Nesse processo o grupo, consensualmente, resolveu aglutinar ambas as proposições, tanto a limitada de Zeca quanto a múltipla de Paula, em um único enunciado para uma nova tarefa, a ser investigada com o auxílio do GeoGebra. É visível como as interações ao redor dessa nova proposição permitem aos licenciandos revisitarem seus conhecimentos e aprofundarem reflexões sobre suas experiências matemáticas (Silver, 1994).

Nas proposições dos enunciados, Zeca (27 intervenções) e Paula (43 intervenções) participaram mais do chat, enquanto Pedro (24 intervenções) acompanhou, endossando proposições, e Ana (6 intervenções) não se manifestou devido a problemas que estava tendo com sua conexão à Internet. $\mathrm{O}$ mediador teve ao total 30 intervenções no chat (item 2.3, Figura 3), na sua grande maioria, acerca de direcionamentos sobre o que se esperava dos participantes nessa primeira sessão. Outros momentos foram relacionados a situar o aluno Pedro, que chegou após ter iniciado a sessão (item 3.3, Figura 3).

\section{$\underline{\text { Segunda sessão "Propondo uma nova tarefa" }}$}

A segunda sessão "Propondo uma nova tarefa" foi marcada para iniciar às 19 horas. Ana e Pedro não puderam participar. Paula foi a primeira a chegar na sala do VMTcG (18:57:18), seguida de Zeca (19:09:02). Os participantes consideraram, como partida para as discussões, a última proposição de enunciado, feita por Paula (Figura 6). Nessa discussão os participantes focaram na resolução do novo enunciado e, diante disso, foram instigados pelo mediador (pesquisador) a usar o GeoGebra.

Mediador (27/11/2019-19:29:57): Vocês propuseram essa questão para ser resolvida usando o GeoGebra, certo?

Zeca (27/11/2019-19:29:58): Sim.

Mediador (27/11/2019-19:30:16): A resolução dela? 


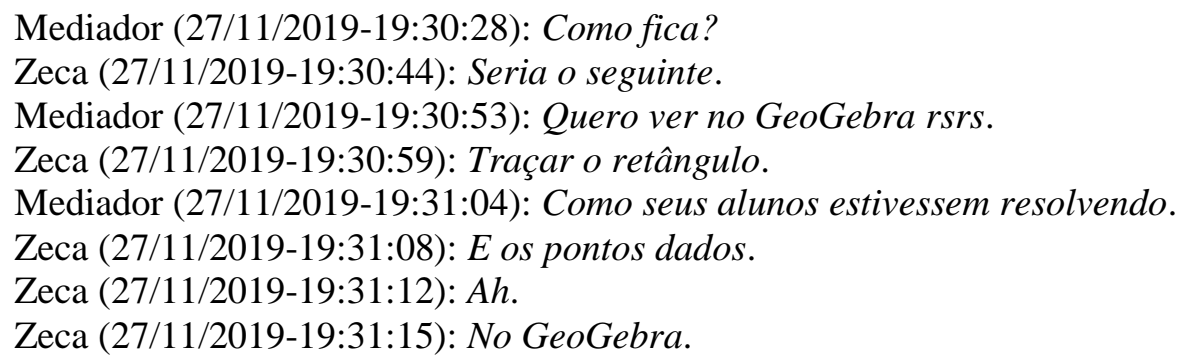

A sincronia da conversa do mediador com o participante Zeca estava sendo estabelecida fora de ordem. Por exemplo, o mediador provoca para que a resolução do novo enunciado seja mostrada no GeoGebra às 19 horas, 29 minutos e 57 segundos, Zeca só reage a essa provocação às 19 horas, 31 minutos e 08 segundos. É um intervalo relativamente pequeno; no entanto, até então Zeca seguia descrevendo como seria a resolução, na qual traçaria o retângulo e marcaria os pontos dados. Nesse ínterim, uma divergência surgiu em relação ao momento do uso do GeoGebra: Paula defendia que o uso do software devesse ocorrer apenas na segunda parte do enunciado, enquanto Zeca defendia que o GeoGebra serviria para encontrar os valores referentes às distâncias.

Paula (27/11/2019-19:31:19): Acredito que o GeoGebra entraria mais na segunda parte. Zeca (27/11/2019-19:31:38): Acho que o GeoGebra iria ajudar na parte de encontrar os valores.

Zeca (27/11/2019-19:31:41): De distância.

Zeca (27/11/2019-19:31:42): Sabe.

Paula (27/11/2019-19:32:09): Sim sim.

Paula (27/11/2019-19:34:13): Acho que essa seria a maior facilitação quando for utilizado $o$ GeoGebra.

Paula (27/11/2019-19:34:27): Você consegue exibir todas as distâncias e comparar.

Zeca conseguiu convencer Paula que o GeoGebra podia ajudar a encontrar os valores das distâncias considerando todo o enunciado, e não resumindo o seu uso apenas à segunda parte, que propunha experimentar outros caminhos além daquele tracejado e do contorno do muro do playground.

No GeoGebra, Zeca seguiu a linha de raciocínio que descreveu para o mediador. Começou a traçar os lados e depois marcou os pontos. O uso do GeoGebra do VMTcG só pode ser feito por um participante de cada vez. Diante disso, mesmo Zeca manuseando o software, ele solicitou que Paula observasse e interferisse, caso ele fizesse algo errado, e Paula aceitou o papel de supervisionar a construção de Zeca. 
Figura 7: Construção de Zeca no GeoGebra do VMT (VMTcG)

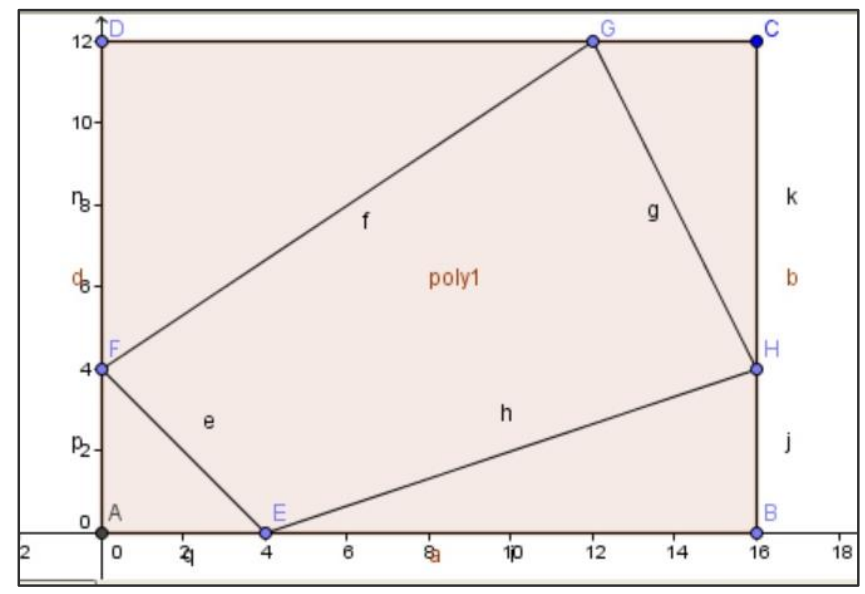

Fonte: VMTcG (2018)

Com a construção terminada, Zeca expôs sua estratégia para encontrar o caminho mais rápido:

Zeca (27/11/2019-19:40:09): Agora que está tudo no GeoGebra.

Zeca (27/11/2019-19:40:09): Só precisamos analisar os valores.

Zeca (27/11/2019-19:40:09): Tais como:

Zeca (27/11/2019-19:40:09): Aplicar o teorema de Pitágoras para achar o valor de h, g, f, e.

Zeca (27/11/2019-19:40:09): E analisar a distância em relação à velocidade dada.

Zeca (27/11/2019-19:40:09): E o caminho que tiver menor tempo.

Zeca (27/11/2019-19:40:09): É isto.

Zeca (27/11/2019-19:40:54): O GeoGebra auxilia na visualização do problema.

Zeca (27/11/2019-19:31:38): Acho que o GeoGebra iria ajudar na parte de encontrar os valores.

Zeca (27/11/2019-19:31:41): de distância.

Zeca (27/11/2019-19:31:42): Sabe.

Paula (27/11/2019-19:32:09): Sim sim.

Paula (27/11/2019-19:34:13): Acho que essa seria a maior facilitação quando for utilizado o GeoGebra.

Paula (27/11/2019-19:34:27): Você consegue exibir todas as distâncias e comparar.

Com a estratégia apresentada e aceita por Paula, os participantes concentraram suas discussões na resolução do enunciado, considerando uma das perguntas iniciais, apresentada pelo mediador juntamente com a atividade de Swan (2014) no início da primeira sessão no quadro branco do VMT: "O que muda (ou não) na solução, quando ela é proposta no papel quadriculado e no GeoGebra?"

Zeca (27/11/2019-19:42:25): E a pergunta sobre fazer no papel quadriculado, daria para fazer da mesma forma.

Zeca (27/11/2019-19:42:26): A minha também.

Zeca (27/11/2019-19:42:35): Certo?

Paula (27/11/2019-19:43:12): Sim, porém no papel seria mais difícil.

Paula (27/11/2019-19:43:27): Quando pergunta se existe outro caminho mais rápido.

Zeca (27/11/2019-19:43:27): Sim. 
Nesse momento Paula questiona se é preciso que eles façam as contas para resolver o enunciado da nova tarefa. O mediador intervém e reforça a necessidade de os participantes resolverem a tarefa com o enunciado proposto por eles, surgindo nas resoluções alguns conteúdos matemáticos e, novamente, discussões sobre a necessidade do uso do GeoGebra:

Paula (27/11/2019-19:57:26): Então, calculando na mão, eu usei perímetro e Pitágoras.

Paula (27/11/2019-19:57:30): Para achar o tempo.

Paula (27/11/2019-19:58:09): Mas se fosse no GeoGebra, poderia colocar para visualizar o valor de $g, h, e, f$.

Zeca (27/11/2019-19:58:21): Eu fiz Pitágoras.

Paula (27/11/2019-19:58:24): Achei que é mais rápido indo pelo muro.

Zeca (27/11/2019-19:58:34): Aí é só calcular os perímetros depois e achar as velocidades.

Tanto Zeca como Paula apresentaram propostas de encontrar medidas para as distâncias, optando pelo cálculo de Pitágoras e perímetros, sem usar o GeoGebra. Mesmo assim, Paula reconheceu que, usando ferramentas do GeoGebra, é possível visualizar os valores correspondentes às distâncias e destacou que o caminho pelo muro é o mais rápido. No entanto, o entendimento de que as ferramentas do GeoGebra facilitam a resolução da tarefa proposta pelo novo enunciado fez com que Paula considerasse outras características para a figura do playground.

Paula (27/11/2019-20:02:31): Cheguei à conclusão de que indo pelo muro anda mais, porém devido à velocidade, é mais rápido.

Paula (27/11/2019-20:03:05): Seria possível a gente deixar os pontos móveis?

Paula (27/11/2019-20:03:15): Que aí tornaria mais interessante.

A ideia de Paula de deixar os pontos móveis acabou fazendo com que o mediador fizesse alguns questionamentos:

Mediador (27/11/2019-20:03:57): Deixar os pontos móveis deixa mais complexo e amplia a importância do GeoGebra na tarefa de vocês?

Paula (27/11/2019-20:03:57): Eu acho que sim, porque se perguntássemos qual seria o melhor caminho, com os pontos móveis no GeoGebra dava para ver vários caminhos.

Entretanto, em momentos pontuais das discussões do mediador com Paula, Zeca estava fazendo algumas movimentações na construção elaborada no GeoGebra (Figura 7). 
Figura 7: Manipulações dos pontos móveis por Zeca no GeoGebra do VMT (VMTcG)

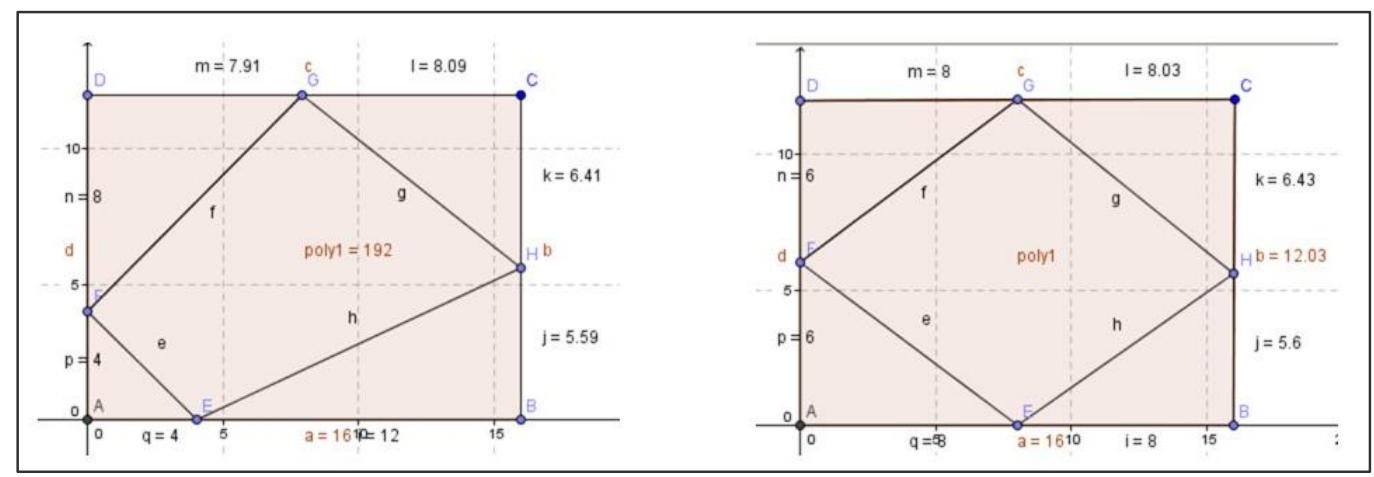

Fonte: VMTcG (2018)

Na Figura 7 a construção de Zeca apresentava os pontos estáticos, porém, com a proposição de Paula e com as manipulações de Zeca, observamos na Figura 8 a mudança da forma do playground. Considerando esse novo contexto para o enunciado, o mediador insiste em novos questionamentos:

Mediador (27/11/2019-20:07:07): Sobre o melhor caminho e os pontos móveis, mesmo assim ainda teria um caminho ideal? Como acharíamos ele?

Paula (27/11/2019-20:09:03): Acredito que quando os pontos estiverem no ponto médio de cada lado.

Zeca (27/11/2019-20:09:04): Acho que se deixar os pontos soltos vai ser muito difícil visualizar o caminho ideal.

Mediador (27/11/2019-20:09:31): Muito difícil, mesmo com o GeoGebra?

Mediador (27/11/2019-20:09:42): Por que os pontos médios Paula?

Paula (27/11/2019-20:11:42): Eu acho que seria o menor quadrilátero inscrito nesse retângulo, mas não tenho certeza.

Nesse momento observamos que o mediador estabeleceu uma conversa direcionada com cada participante, intercalando provocações para Paula e para Zeca. Paula posteriormente esclarece melhor essa questão de deixar os pontos móveis para valorizar o uso do GeoGebra, desencadeando a necessidade de modificação, no enunciado até então considerado, para a nova tarefa.

Paula (27/11/2019-20:16:16): Eu estava pensando e achei que a maior questão para passar aquela questão feita no papel para o GeoGebra foi a localização dos pontos.

Paula (27/11/2019-20:16:31): Que lá era fixa e agora é dado os pontos móveis.

Paula (27/11/2019-20:16:50): É trabalho com essa questão de poder manipular e observar vários exemplos.

Mediador (27/11/2019-20:17:20): Sim, oportuniza múltiplas respostas.

Paula (27/11/2019-20:17:52): E ativando o valor das distâncias seria possível ver quando seria uma maior ou menor distância. E relacionando com a velocidade deixaria mais interessante essa investigação.

Paula (27/11/2019-20:17:57): O que acha, Zeca?

Zeca (27/11/2019-20:18:48): Achei muito boa a ideia.

Zeca (27/11/2019-20:18:57): Só não sei como ficaria no GeoGebra.

Zeca (27/11/2019-20:19:06): Você consegue reproduzir.

Zeca $(27 / 11 / 2019-20: 19: 07):$ ? 
Paula (27/11/2019-20:20:10): Então, acredito que já esteja montado, porém seria necessário outro enunciado.

Com a proposição dos pontos móveis de Paula, Zeca considerou necessária uma nova construção no GeoGebra. Essa provocação de Zeca acabou fazendo com que Paula reconhecesse a necessidade de outro enunciado para que os pontos pudessem ser semidependentes. Quando questionada pelo mediador sobre o porquê de um novo enunciado, Paula justifica seu pensamento e determina o tipo de tarefa a ser proposta, usando o GeoGebra.

Paula (27/11/2019-20:22:55): E a questão dos pontos móveis quebra a hipótese de que fora da linha tracejada é outra velocidade, já que não é mais essa a proposta pelo o que eu entendi.

Mediador (27/11/2019-20:23:24): Então com os pontos móveis seria mais uma tarefa de exploração?

Paula (27/11/2019-20:24:22): Acredito que sim, mas não deixando de lado os conteúdos matemáticos, visto que é necessário utilizar perímetro.

Paula (27/11/2019-20:24:58): E por trás de tudo, o fato de que o polígono formado pela ligação dos pontos médios ser o menor.

Paula (27/11/2019-20:25:03): Eu acho.

Paula (27/11/2019-20:25:11): Não tenho certeza se é isso mesmo.

Além das ideias lançadas no chat acerca dos pontos móveis e do uso do cálculo do perímetro, Paula também manipulou a construção feita por Zeca no GeoGebra do VMT, para identificar as medidas dos lados, e no posicionamento dos pontos do playground o mais próximo possível dos pontos médios dos lados do muro (Figura 8), reforçando sua tese de que o caminho mais curto seria formado pelo quadrilátero inscrito cujos vértices estivessem nos pontos médios dos lados do muro.

\section{Figura 8: Paula manipulando no GeoGebra do VMTcG}

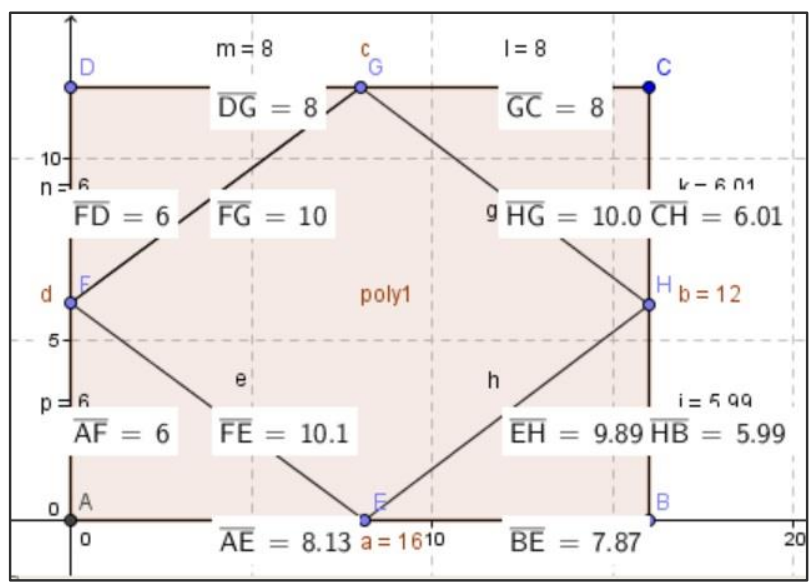

Fonte: VMTcG (2018)

Diante de todas as modificações sugeridas por Paula, o mediador questionou como ficaria o enunciado. Paula argumentou que sua ideia mudaria a questão, já que o enunciado 
abordaria a localização dos pontos, de modo que as crianças ${ }^{6}$ percorressem o menor caminho. Nesse momento, Zeca, que até então estava ausente das discussões, começou a sugerir o que poderia ser alterado no enunciado.

Zeca (27/11/2019-20:28:29): Você pode alterar como algo do tipo.

Zeca (27/11/2019-20:28:29): Manipule os pontos de forma que percorra o menor caminho possivel.

Zeca (27/11/2019-20:28:35): Desconsiderando velocidade.

Zeca (27/11/2019-20:28:35): Agora.

Paula (27/11/2019-20:29:57): Sim.

Nessa segunda sessão os participantes inicialmente assumiram como objetivo coletivo solucionar o primeiro enunciado elaborado na primeira sessão (item 2.2, Figura 3). Nessa colaboração escolhemos episódios a respeito do uso do GeoGebra e de como ele afetava o enunciado até então considerado pelos participantes (item 3.1, Figura 3). E, nesse episódio, identificamos que os participantes perceberam como o software tornava simples a tarefa do novo enunciado, em comparação com a solução dessa mesma tarefa, fazendo uso do Teorema de Pitágoras e do cálculo dos perímetros.

Essas reflexões repercutiram na identificação, pelos participantes, da principal diferença entre a atividade de Swan (2014), em que os vértices do caminho tracejado do playground eram fixos, e a do novo enunciado, que, considerando o GeoGebra, deveria ter a figura alterada com esses vértices móveis e sem o tracejado da figura. Essas modificações na figura levaram os participantes a considerar um enunciado que promovesse a exploração de caminhos, deixando a tarefa sem uma quantidade finita de respostas.

Nessa segunda sessão Paula trouxe mais questionamentos que modificaram o rumo da sessão (66 intervenções), seguida de Zeca, que também colaborou problematizando/concordando/alterando o que era proposto (106 intervenções). O mediador teve maior protagonismo em relação à primeira sessão, com 79 intervenções (item 2.3, Figura 3), que foram além de direcionar os participantes para o que se esperava da tarefa de elaborar uma nova proposta. Ele provocou Paula com relação ao uso do GeoGebra, o que a fez concluir que as potencialidades do software usadas na resolução tornavam simples o enunciado elaborado, e que a melhor forma de aproveitar essa ferramenta seria transformar o enunciado em uma tarefa de exploração, abrindo para várias soluções, e deixar de lado o

\footnotetext{
${ }^{6}$ As crianças que Paula citou, são parte do contexto da atividade original de Swan (2014), apresentada na Figura 1. São os alunos hipotéticos.
} 
tracejado antes determinado na atividade de Swan (2014) e o elemento velocidade incluído e aprovado por todos na primeira sessão (item 3.3, Figura 3).

\section{Fase 4}

Nesta fase escolhemos estudar como contraste as interações dos participantes nas sessões "Propondo uma nova tarefa" no ambiente VMTcG. Na primeira sessão, Zeca apresentou um enunciado que permitia a escolha de dois caminhos e a inclusão do elemento velocidade; Pedro e Paula inicialmente concordaram. No entanto, Paula argumentou que seria interessante não fixar a nova tarefa apenas em duas possíveis soluções; Zeca e Pedro concordaram. Na segunda sessão, Paula, instigada pelo mediador e visando às potencialidades do GeoGebra, chegou à conclusão de transformar o enunciado em uma tarefa exploratória, permitindo uma multiplicidade maior de respostas; Zeca concordou com a sugestão e concluiu que o elemento velocidade, antes colocado por ele na primeira sessão, não faria mais sentido nesse novo cenário proposto por Paula. Dessa forma, entendemos que a comunicação estabelecida no VMTcG configurou um processo social em que os participantes trocaram informações, influenciando-se reciprocamente, na elaboração e na proposição colaborativa da nova tarefa (Menezes et al., 2014; Ponte \& Menezes, 2000).

Na segunda sessão, em determinado momento Zeca representou a figura da atividade de Swan (2014) no GeoGebra (Figura 7). Em seguida Paula começou a problematizar os pontos fixos dessa figura, e quase simultaneamente Zeca a modificava no GeoGebra, deixando os pontos móveis e experimentando novos formatos (Figura 8). Por sua vez, Paula, ao defender sua proposta de pontos móveis e o uso do cálculo dos perímetros, manipulou essa figura no GeoGebra, identificando as medidas dos lados (Figura 9). Temos nesse cenário interações que configuraram uma forma de comunicação entre os participantes, e entre os participantes e o GeoGebra (Bairral, 2015).

Considerando interações colaborativas na proposição de uma tarefa por licenciandos em matemática num ambiente online, síncrono e integrado ao GeoGebra, pudemos, a partir do que foi descrito e analisado nas fases 1, 2, 3 e 4, ilustrar enunciados, interações e conteúdos matemáticos que emergiram das interações no VMTcG, na proposição de uma nova tarefa. 
Interações e enunciados emergentes, quando "a brincadeira consiste em tocar os brinquedos e voltar para o ponto inicial"

Sobre os enunciados propostos pelos participantes, observamos as alterações que modificaram a atividade inicial de Swan (2014), antes caracterizada por um problema fechado a ser desenvolvido em uma malha quadriculada e posteriormente modificada, passando a ser um problema aberto, no qual a exploração auxiliada pelas ferramentas do GeoGebra é requerida (Quadro 2).

\section{Quadro 2: Enunciados em processo de análise e de proposição}

Swan (2014): Esta é a vista do plano de um playground de 12 por 16 metros. Cada criança inicia no ponto $\mathrm{S}$, que está a $4 \mathrm{~m}$ ao longo do muro de $16 \mathrm{~m}$. Elas têm que correr e tocar cada um dos outros 3 pontos e voltar ao ponto $\mathrm{S}$. A primeira criança que retomar ao ponto $\mathrm{S}$ é vencedora. Qual é o menor trajeto?

\begin{tabular}{|l|l|}
\hline Zeca (13/11/2018-19:52:41): & Paula (13/11/2018-20:27:18): Em um \\
Num brinquedo playground, & playground de formato retangular \\
cada criança inicia do ponto & medindo 12x16 m, um animador de festa \\
S, que está a 4 m ao longo & inicia uma brincadeira com as crianças. \\
do muro de $16 \mathrm{~m}$. Elas têm & A brincadeira consiste em tocar os \\
que correr e tocar cada um & brinquedos e voltar para o ponto inicial. \\
dos 3 vértices pontilhados, e & Vence a criança que voltar primeiro para \\
voltar ao ponto S. Sabendo & o ponto de partida. Sabendo que sobre o \\
que pelo caminho pontilhado & caminho tracejado a velocidade máxima \\
existem obstáculos e sua & obtida será de $1 \mathrm{~m} / \mathrm{s}$ e pelo caminho dos \\
velocidade se reduz para 1 & muros é de $2 \mathrm{~m} / \mathrm{s}$. Qual seria o melhor \\
m/s e pelo caminho do muro & caminho para a criança sair vencedora? \\
a velocidade é de $2 \mathrm{~m} / \mathrm{s}$. & Agora considerando que toda área fora \\
Qual o melhor trajeto? & do caminho pontilhado teria uma \\
& velocidade de $2 \mathrm{~m} / \mathrm{s}$, conseguiríamos \\
& encontrar um caminho melhor que o \\
& escolhido anteriormente?
\end{tabular}

Combinação de ideias de Paula (13/11/2018-20:27:18) e Zeca (27/11/2019-20:28:29): Em um playground de formato retangular medindo $12 \times 16 \mathrm{~m}$, um animador de festa inicia uma brincadeira com as crianças. A brincadeira consiste em tocar os brinquedos e voltar para o ponto inicial. Vence a criança que voltar primeiro para o ponto de partida. Manipule os pontos de forma que percorra o menor caminho possível.

Fonte: Autores (2020)

Nas interações dos participantes no VMTcG essas modificações se deram inicialmente por meio da proposição de Zeca, que foi avaliada e aceita em parte pelo grupo, e no decorrer das sessões novas modificações foram feitas, conforme proposições de resolução da atividade inicial, combinadas com o manuseio da figura do playground no GeoGebra. Outro destaque é a forma como os participantes interagiam, aceitando sugestões e modificações das suas proposições (Quadro 3). 
Quadro 3: Interações online potencializando a proposição

\begin{tabular}{|c|c|c|}
\hline $\begin{array}{l}\text { Paula }(13 / 11 / 2018-19: 57: 22) \text { : } \\
\text { Eu acho que poderíamos não } \\
\text { restringir a somente dois } \\
\text { caminhos }\end{array}$ & $\begin{array}{l}\text { Zeca }(27 / 11 / 2019-19: 31: 38) \text { : } \\
\text { Acho que o GeoGebra iria } \\
\text { ajudar na parte de encontrar } \\
\text { os valores } \\
\text { Paula (27/11/2019- } \\
\text { 19:34:27): Você consegue } \\
\text { exibir todas as distâncias e } \\
\text { comparar }\end{array}$ & $\begin{array}{l}\text { Paula (27/11/2019-20:03:05): Seria } \\
\text { possível a gente deixar os pontos móveis? } \\
\text { Paula }(27 / 11 / 2019-20: 03: 15) \text { : Que aí } \\
\text { tornaria mais interessante } \\
\text { Zeca }(27 / 11 / 2019-20: 09: 04) \text { : Acho que se } \\
\text { deixar os pontos soltos vai ser muito } \\
\text { dificil visualizar o caminho ideal } \\
\text { Paula (27/11/2019-20:11:42): Eu acho } \\
\text { que seria o menor quadrilátero inscrito } \\
\text { nesse retângulo, mas não tenho certeza }\end{array}$ \\
\hline
\end{tabular}

Fonte: Autores (2020)

No que diz respeito aos conteúdos emergentes, a situação inicial (na malha quadriculada) envolvia a aplicação do Teorema de Pitágoras. Todavia, as interações online e as particularidades do VMTcG propiciaram a emergência de outros conteúdos matemáticos, como: intervalos, análise de distância, ponto médio, formas poligonais, quadriláteros inscritos, perímetros; como apontados nos chats do Quadro 4.

\section{Quadro 4: Conteúdos matemáticos que emergiram}

\begin{tabular}{|c|c|c|}
\hline $\begin{array}{l}\text { Paula (13/11/2018- } \\
\text { 19:52:09): Envolveria } \\
\text { triângulos também } \\
\text { Paula (13/11/2018- } \\
\text { 19:53:26): Eu pensei } \\
\text { envolver velocidade } \\
\text { também }\end{array}$ & $\begin{array}{l}\text { Zeca }(27 / 11 / 2019-19: 40: 09) \text { : } \\
\text { Aplicar o teorema de } \\
\text { Pitágoras para achar o valor } \\
\text { de h, g, f, e } \\
\text { Paula }(27 / 11 / 2019 \text { - } \\
\text { 19:57:26): Então, calculando } \\
\text { na mão, eu usei perímetro e } \\
\text { Pitágoras }\end{array}$ & $\begin{array}{l}\text { Paula (27/11/2019-20:09:03): Acredito que } \\
\text { quando os pontos estiverem no ponto médio de } \\
\text { cada lado } \\
\text { Paula (27/11/2019-20:11:42): Eu acho que seria } \\
\text { o menor quadrilátero inscrito nesse retângulo, } \\
\text { mas não tenho certeza } \\
\text { Paula (27/11/2019-20:24:22): Acredito que sim, } \\
\text { mas não deixando de lado os conteúdos } \\
\text { matemáticos, visto que é necessário utilizar } \\
\text { perímetro } \\
\text { Paula (27/11/2019-20:24:58): E por trás de } \\
\text { tudo, o fato de que o polígono formado pela } \\
\text { ligação dos pontos médios ser o menor }\end{array}$ \\
\hline
\end{tabular}

Fonte: Autores (2020)

Vemos que a dinâmica formativa favoreceu a proposição de situações criativas e autorais mediante reflexões com espírito colaborativo. A análise suscita, também, um processo reflexivo retroalimentativo entre as três fases envolvidas na proposição de problemas (proposição inicial, resolução propriamente dita e sugestões adicionais) de Silver et al. (1996). Embora em nossa pesquisa estivéssemos orientados pela proposição, cabe análise futura para verificar se esse imbricamento das fases ocorre na ambiência do VMTcG.

Sobre a aprendizagem nesse ambiente síncrono observamos, influenciados por Stahl (2006) e Stahl et al. (2008), que o aprendizado foi se dando no decorrer das interações entre os participantes ao compartilharem aprendizados trazidos por eles para a sessão online ou 
adquiridos na manipulação da aba GeoGebra, configurando ao final uma adaptação da atividade de Swan (2014) que não era inteiramente do Zeca, da Paula, do Pedro, ou do mediador, mas, um agrupamento de ideias que foram testadas, confrontadas, repensadas, modificadas, aceitas, recusadas pelo grupo. Assim, a adaptação colaborativa da tarefa mostrou que houve aprendizagem na medida que os participantes coletivamente agregaram aprendizados individuais em um produto do grupo.

\section{Conclusão}

Neste artigo ilustramos e analisamos licenciandos interagindo sincronicamente na reformulação - com o uso do GeoGebra - de uma atividade cujo propósito era estudar o trajeto sugerido em uma malha quadriculada. A indicação do pontilhado na malha, com esse recurso, indicava o uso de Teorema de Pitágoras para descobrir os lados do caminho tracejado, que formavam um quadrilátero.

A análise da reflexão colaborativa no ambiente permitiu observar particularidades: os participantes propuseram uma nova tarefa, a partir de uma atividade inicial que foi sendo modificada conforme condições permitidas no/pelo ambiente do VMTcG, o que gerou um grupo de enunciados (Quadro2), em que os objetivos de resolução foram modificados de acordo com a tecnologia proposta para o problema ser solucionado: antes, malha quadriculada; e depois, GeoGebra.

Mesmo não nos baseando pelas três fases de Silver et al. (1996), nos destaques dos Quadros 2, 3 e 4 percebemos como, a partir da atividade inicial, os participantes puderam solucionar e propor novos problemas alterados mediante negociações e interações no ambiente VMTcG e indicando que as fases podiam ocorrer simultaneamente. Ao analisar a situação inicial e ao resolvê-la usando o GeoGebra, os participantes propunham novos enunciados, que iam sendo ajustados conforme novas interações entre os participantes, e interações entre estes e o ambiente VMTcG.

As interações online potencializaram a investigação e a reelaboração da tarefa e possibilitaram sua solução com o auxílio do GeoGebra. As interações aconteceram entre os participantes, principalmente entre Zeca e Paula, e entre os participantes e o GeoGebra do VMT. Dentre elas, destacamos: o acrescentar de informações (a variável velocidade, pelo participante Zeca), o repensar de ideias (Paula, considerando a inclusão do GeoGebra, entendeu que a tarefa deveria ser exploratória), o convencimento de e a partir de ideias 
(Paula apresentou um novo cenário e Zeca concluiu que a variável velocidade precisava ser desconsiderada).

As interações dos participantes no VMTcG também permitiram que os licenciandos configurassem uma nova tarefa a ser proposta nesse tipo de ambiente. Que tipo de tarefa os participantes propuseram? Uma tarefa pensada colaborativamente para ser solucionada com o GeoGebra e com o cálculo de perímetros. Essa combinação de ferramentas potencializou a experimentação de vários trajetos e configurou assim um problema aberto e possível de ser explorado com o GeoGebra e com indicação de mais de uma solução.

A reformulação da atividade pelos participantes mediante as interações online no VMTcG permitiu que eles solucionassem as proposições formuladas, caracterizando um processo de resolução e apresentação de um problema que, mediado pelo GeoGebra, torna sua(s) solução(ões) mais acessível(eis). A vivência formativa de reformular uma atividade para uma tarefa a ser desenvolvida com o GeoGebra permitiu que os graduandos respondessem de forma a refletir seus posicionamentos e valores, personalizando e humanizando a atividade de Swan (2014) e, consequentemente, a matemática dela oriunda (Silver, 1994).

Esse movimento colaborativo, vivenciado com as interações síncronas, mostra como a reflexão coletiva, o compartilhamento e a negociação constante de ideias matemáticas articuladas aos possíveis enunciados estão intrinsecamente relacionadas às multirrepresentações (escritos no chat, construções no GeoGebra e outros registros) favorecidas pelo VMTcG. Em contrapartida, o que consideramos ser um potencial desse ambiente (múltiplas ferramentas interativas, de construção e de reflexão coletiva), acaba sendo também seu ônus, na medida em que, por torná-lo robusto, dificulta a conexão do VMTcG para alguns licenciandos. No entanto, mesmo com dificuldades de acesso, o ambiente VMTcG mostra-se muito frutífero na proposição de tarefas, processo que vimos ser retroalimentado pelas reflexões relacionadas à resolução da situação em análise e com seus diferentes enunciados.

Pontos desfavoráveis no uso do ambiente VMTcG foram referentes a conexão, já que o ambiente por sua robustez requeria uma boa conexão com a internet, o que em determinados momentos da sessão implicava em travamentos que exigiam dos participantes desconectar e conectar novamente ao ambiente. Esses momentos interrompiam diálogos ou linhas de raciocínios que estavam acontecendo. No entanto, não foi impeditivo para a 
realização da tarefa, assemelhando-se a intempéries possíveis de surgir quando do desenvolvimento de atividades no ensino virtual ou presencial. Desde 2019 esses problemas foram minorados, já que o VMTcG migrou para um site ${ }^{7}$ na internet, podendo ser acessado até de aparelhos celulares.

Em meio a pandemia do novo Coronavírus e de demandas diversas para trabalho remoto pesquisas como a que apresentamos são relevantes por permitir discutir uma proposta de educação online que potencializa processos de ensino e de aprendizagem colaborativo e crítico, sendo mais uma opção a ser considerada quando professores e alunos são privados de interagir presencialmente.

\section{Referências}

Bairral, M. A. (2015). Pesquisas em educação matemática com tecnologias digitais: Algumas faces da interação. Perspectivas da Educação Matemática, 18(8), 485-505. https://periodicos.ufms.br/index.php/pedmat/article/view/1460/967.

Bairral, M. A. (2018). Discurso, interação e aprendizagem matemática em ambientes virtuais a distância (2.a edição). Edur. (Original publicado em 2007)

Carmo, H. \& Ferreira, M. M. (2008). Metodologia da investigação: Guia para autoaprendizagem. Universidade Aberta.

César, M. (2000). Interacções na aula de Matemática: Um percurso de 20 anos de investigação e reflexão. Em C. Monteiro, F. Tavares, J. Almino, J. P. da Ponte, J. M. Matos e L. Menezes (Eds.), Interacções na aula de Matemática (Vol. 1, pp. 13-34). Sociedade Portuguesa de Ciências da Educação.

Gonçalves, M. F. (2000). Interacções e comunicação na aula de Matemática: Implicações para o currículo e a formação de professores. Em C. Monteiro, F. Tavares, J. Almino, J. P. da Ponte, J. M. Matos e L. Menezes (Eds.), Interacções na aula de Matemática (pp. 191-199). Sociedade Portuguesa de Ciências da Educação.

Martins, J. \& Bicudo, M. A. V. (2005). A pesquisa qualitativa em psicologia: Fundamentos e recursos básicos (5.a edição). Centauro. (Original publicado em 1994)

Menezes, L., Ferreira, R. T., Martinho, M. H. \& Guerreiro, A. (2014). Comunicação nas práticas letivas dos professores de Matemática. Em J. P. da Ponte (Ed.), Práticas profissionais dos professores de Matemática (Vol. 1, pp. 135-161). Instituto de Educação da Universidade de Lisboa.

Mercado, L. P. L. (2009). Integração de mídias nos espaços de aprendizagem. Em aberto, 22(79), 17-44. http://portal.inep.gov.br/informacao-da-publicacao/lasset_publisher/6JYIsGMAMkW1/document/id/492517.

Monteiro, C., Tavares, F., Almino, J., Ponte, J. P. da, Matos, J. M. \& Menezes, L. (2000). Interacções na aula de Matemática. Sociedade Portuguesa de Ciências da Educação.

\footnotetext{
${ }^{7}$ https://vmt.mathematicalthinking.org/
} 
Nacarato, A. M. \& Lopes, C. E. (2005). Escritas e leituras na Educação Matemática. Autêntica Editora.

Pedrosa, M. H. (2000). A comunicação na sala de aula: As perguntas como elementos estruturadores da interacção didáctica. Em C. Monteiro, F. Tavares, J. Almino, J. P. da Ponte, J. M. Matos e L. Menezes (Eds.), Interacções na aula de Matemática (pp. 149161). Sociedade Portuguesa de Ciências da Educação.

Ponte, J. P. da \& Menezes, L. (2000). Prefácio. Em C. Monteiro, F. Tavares, J. Almino, J. P. da Ponte, J. M. Matos e L. Menezes (Eds.), Interacções na aula de Matemática (pp. 9-11). Sociedade Portuguesa de Ciências da Educação.

Powell, A. B. \& Bairral, M. A. (2006). A escrita e o pensamento matemático: Interações e potencialidades. Papirus.

Powell, A. B. \& Pazuch, V. (2016). Tarefas e justificativas de professores em ambientes virtuais colaborativos de geometria dinâmica. Zetetiké, 24(2), 191-207. https://doi.org/10.20396/zet.v24i2.8646517.

Romão, M. (2000). O papel da comunicação na aprendizagem da matemática. Em C. Monteiro, F. Tavares, J. Almino, J. P. da Ponte, J. M. Matos e L. Menezes (Eds.), Interacções na aula de Matemática (pp. 163-177). Sociedade Portuguesa de Ciências da Educação.

Silver, E. A. (1994). On mathematical problem posing. For The learning of Mathematics, 14(1), 19-28. http://www.jstor.org/stable/40248099.

Silver, E. A., Mamona-Downs, J., Leung, S. S. \& Kenney, P. A. (1996). Posing mathematical problems: An exploratory study. Journal for Research in Mathematics Education, 27(3), 293-309. https://www.jstor.org/stable/749366.

Souza, R. M. \& Bairral, M. A. (2016). Acessar ou interagir? Uma análise em disciplinas da licenciatura em Matemática no Cederj. EAD em Foco, 6(3), 39-49. https://doi.org/10.18264/eadf.v6i3.356.

Stahl, G. (2006). Group cognition: Computer support for building collaborative knowledge. MIT.

Stahl, G., Koschmann, T. \& Suthers, D. (2008). Aprendizagem colaborativa com suporte computacional: Uma perspectiva histórica. Boletim Gepem, (53), 11-42. http://costalima.ufrrj.br/index.php/gepem/article/download/75/209.

Swan, M. (2014). Designing tasks and lessons that develop conceptual understanding, strategic competence and critical awareness. In J. Brocardo, A. M. Boavida, C. Delgado, E. Santos, F. Mendes, J. Duarte, M. Baía \& M. Figueiredo (Comps.), Tarefas matemáticas. Encontro de Investigação em Educação Matemática (pp. 9-28). Sociedade Portuguesa de Investigação em Educação Matemática. http://www.rdpc.uevora.pt/bitstream/10174/13646/1/ATAS-EIEM2014.pdf. 
Autores

Rhômulo Oliveira Menezes

Mestre em Educação em Ciências e Matemática pela Universidade Federal do Pará (UFPA, Brasil). Doutorando em Educação em Ciências e Matemáticas pelo Programa de Pós-Graduação em Educação em Ciências e Matemáticas da Universidade Federal do Pará. Professor da Secretaria de Educação do Estado do Pará (SEDUC/PA). Temas de pesquisa: Modelagem Matemática; Tecnologias Digitais voltadas para o Ensino de Matemática; Educação Online. E-mail: rhominho.oliveira@ hotmail.com

Marcelo Almeida Bairral Doutor em Educação Matemática pela Universidade de Barcelona (Espanha). Pós-doutor em Educação Matemática pela Universidade do Estado de Nova Jersey (EUA), e pela Universidade de Turin (Itália). Professor Titular da Universidade Federal Rural do Rio de Janeiro (Brasil). Presidente da Sociedade Brasileira de Educação Matemática (gestão jul./2019-jul./2022). Temas de pesquisa: Interações em ambientes virtuais; Tecnologias e formação de professores; Aprendizagem matemática em dispositivos móveis com toques em tela; Inovações curriculares em geometria. E-mail: $\underline{\text { mbairral@ufrrj.br }}$ 